\title{
Pentacecilides, new inhibitors of lipid droplet formation in mouse macrophages, produced by Penicillium cecidicola FKI-3765-1: I. Taxonomy, fermentation, isolation and biological properties
}

\author{
Hiroyuki Yamazaki ${ }^{1}$, Kakeru Kobayashi ${ }^{1}$, Daisuke Matsuda ${ }^{1}$, Kenichi Nonaka ${ }^{2}$, Rokuro Masuma ${ }^{2}$, \\ Satoshi Ōmura ${ }^{2}$ and Hiroshi Tomoda ${ }^{1}$ \\ New compounds designated pentacecilides $\mathrm{A}$ to $\mathrm{C}$ were isolated from the fermentation broth of Penicillium cecidicola \\ FKI-3765-1 by solvent extraction, silica gel column chromatography and preparative HPLC. Pentacecilides A and B dose- \\ dependently inhibited lipid droplet formation in mouse macrophages. Furthermore, pentacecilides $A$ and $B$ were found to inhibit \\ the synthesis of cholesteryl ester in mouse macrophages with respective $\mathrm{IC}_{50}$ values of 3.65 and $4.76 \mu \mathrm{m}$ without any cytotoxic \\ effect, but pentacecilide $C$ showed almost no activity. The study of the mechanism of action strongly suggested that \\ pentacecilides $A$ and $B$ inhibit acyl-CoA: cholesterol acyltransferase activity in macrophages.
}

The Journal of Antibiotics (2009) 62, 195-200; doi:10.1038/ja.2009.18; published online 20 March 2009

Keywords: acyl-CoA:cholesterol acyltransferase; fungal metabolite; inhibitor; lipid droplet formation; Penicillium cecidicola; pentacecilide; thailandolide

\section{INTRODUCTION}

In the early stage of atherosclerogenesis, macrophages penetrate the intima, efficiently take up modified low-density lipoprotein, store cholesterol and fatty acid as a respective form of cholesteryl ester (CE) and triacylglycerol (TG) in cytosolic lipid droplets, and are converted into foam cells, leading to the development of atherosclerosis in the arterial wall. Therefore, inhibition of lipid droplet accumulation in macrophages would be expected to retard the progression of atherosclerosis. $^{1-4}$

In the course of our screening program for microbial inhibitors of lipid droplet formation in mouse macrophages, ${ }^{5-10}$ three new compounds designated pentacecilides A to $\mathrm{C}$ (Figure 1), structurally related to known thailandolides $\mathrm{A}$ and $\mathrm{B},{ }^{11}$ were isolated from the culture broth of a soil-isolated fungus, FKI-3765-1. Thailandolides were originally isolated as fungal metabolites from Talaromyces thailandiasis, ${ }^{11}$ and were not isolated from the culture broth of strain FKI-3765-1. Pentacecilides A and B were found to inhibit lipid droplet formation in mouse macrophages, although the biological activity of thailandolides has not been reported. The structure elucidation of pentacecilides will be described in an accompanying study. ${ }^{12}$ In this study, the taxonomy of the producing strain, fermentation, isolation and biological properties of pentacecilides $\mathrm{A}$ to $\mathrm{C}$ are described.

\section{RESULTS}

Taxonomy of strain FKI-3765-1

Colonies on Czapek yeast agar (CYA) after 7 days at $25^{\circ} \mathrm{C}$ (Figure 2a) were $44-45 \mathrm{~mm}$ in diameter, dense, colliculose, floccose to funiculose, with a smooth margin and white (a). The center of the colony was dark olive ( $1 \mathrm{pn})$ in conidial color, exuding clear drops. The reverse side was dark brown ( 5 pn). Colonies on malt extract agar (Figure 2b) were $49-51 \mathrm{~mm}$ in diameter, dense, colliculose, floccose, with a smooth margin, and white (a), without exudate drops. The reverse side was amber $(3 \mathrm{lc}$ ). Colonies on G25N (Figure 2c) were $5.0-7.0 \mathrm{~mm}$ in diameter, pulvinate, floccose, with a smooth margin, and bamboo ( $2 \mathrm{gc}$ ) in color, without exudate drops. The reverse side was bamboo ( 2 gc). Colonies on CYA after 7 days at $37^{\circ} \mathrm{C}$ were dense, colliculose, floccose to funiculose, with a smooth margin, and sand (2 ec) in color. The reverse was cork tan (4 ic). The colony on CYA at $5.0^{\circ} \mathrm{C}$ showed no growth.

Conidiophores on CYA were from basal hyphae, rarely branching, $17.5-65 \times 2.5-3.5 \mu \mathrm{m}$, with a smooth wall. Penicilli from condiophores were biverticillate (consisting of metulae and phialides) and symmetrical (Figure 2d). Metulae were 3-7 branches, which were usually rather appressed or sometimes slightly divergent of larger size, $10-12.5 \times 2.5-2.7 \mu \mathrm{m}$. Phialides were acerose, $10-15 \times 2.5-3.0 \mu \mathrm{m}$,

${ }^{1}$ Graduate School of Pharmaceutical Sciences, Kitasato University, Shirokane, Minato-ku, Tokyo, Japan and ${ }^{2}$ Kitasato Institute for Life Sciences, Kitasato University, Shirokane, Minato-ku, Tokyo, Japan

Correspondence: Professor H Tomoda, Graduate School of Pharmaceutical Sciences, Kitasato University, 5-9-1 Shirokane, Minato-ku, Tokyo 108-8641, Japan. E-mail: tomodah@pharm.kitasato-u.ac.jp

Received 15 January 2009; revised 6 February 2009; accepted 10 February 2009; published online 20 March 2009 


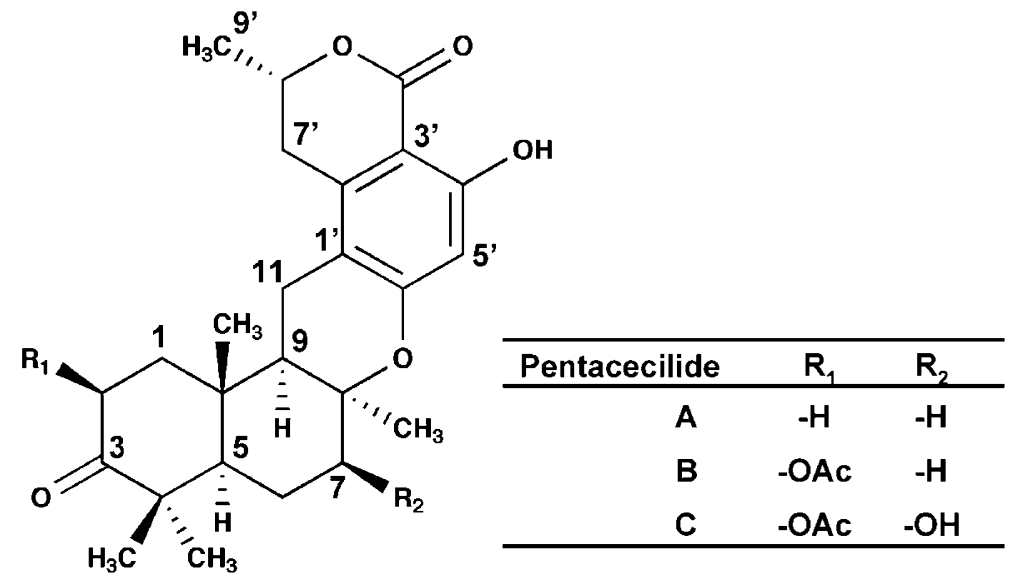<smiles>C[C@H]1Cc2c(cc(O)c3c2C[C@]2(C)[C@]3(C)[C@@H](O)C[C@H]3C(C)(C)C(=O)CC[C@@]32C)OC1=O</smiles>

Thailandolide A<smiles>CC(=O)O[C@H]1c2c(c(O)cc3c2[C@]2(C)[C@](C)(O3)[C@@H](O)C[C@H]3C(C)(C)C(=O)C=C[C@]32C)C(=O)O[C@@H]1C</smiles>

Thailandolide B

Figure 1 Structures of pentacecilides $A$ to $C$ and thailandolides $A$ and $B$.

with smooth walls. Conidia were subglobose to globose, smoothwalled, $2.7-3.5(5.0) \times 2.3-3.0 \mu \mathrm{m}$ in size, and with divergent long chains (Figure 2e).

From the above morphological characteristics, strain FKI-3765-1 was considered to belong to genus Penicillium in the subgenus Biverticillium Section Simplicia. ${ }^{13}$ Furthermore, from the characteristics of the mycelial colors on CYA, the rapid growth at $37^{\circ} \mathrm{C}$ on CYA and the length of conidiophores, the strain was considered to be Penicillium cecidicola. In addition, the ITS rDNA sequence (550 nucleotides) of strain FKI-3765-1 showed $99.4 \%$ similarity to that of Penicillium cecidicola (strain name) (accession no. AY787844). As a result, the producing strain FKI-3765-1 was identified as P. cecidicola.

\section{Isolation}

The 15-day-old whole broth $(250 \mathrm{~g})$ was extracted with 0.501 of acetone. After the acetone extracts were filtered and concentrated to remove acetone, the aqueous solution was extracted with ethyl acetate. The extracts were dried over $\mathrm{Na}_{2} \mathrm{SO}_{4}$ and concentrated in vacuo to dryness to yield a red brown material $(438 \mathrm{mg})$. The material was dissolved in hexane-ethyl acetate $(2: 1, \mathrm{v} / \mathrm{v})$, applied to a silica gel column $(10 \mathrm{~g})$, and eluted stepwise with $2: 1(\mathrm{v} / \mathrm{v})$ of hexane-ethyl acetate and $100: 0,10: 1,5: 1,1: 1$ and $0: 100(\mathrm{v} / \mathrm{v})$ of $\mathrm{CHCl}_{3}-\mathrm{CH}_{3} \mathrm{OH}$ (100 $\mathrm{ml}$ for each solvent). Active fractions from a 5:1 solvent contain- ing pentacecilides were concentrated in vacuo to dryness to give a red brown oily material $(171 \mathrm{mg})$. The material was finally purified by preparative HPLC (column; PEGASIL ODS (Senshu Scientific Co. Ltd, Tokyo, Japan), $20 \times 250 \mathrm{~mm}$; solvent, $70 \% \mathrm{CH}_{3} \mathrm{CN}$; detection, $\mathrm{UV}$ at $210 \mathrm{~nm}$; flow rate, $8.0 \mathrm{ml} \mathrm{min}^{-1}$ ). Under these conditions, pentacecilides A to $C$ were eluted as a peak with a retention time of $30.5,27.3$ and $12.7 \mathrm{~min}$, respectively (Figure 3 ). The fractions were concentrated in vacuo to dryness to give pure pentacecilides A $(4.47 \mathrm{mg}), \mathrm{B}$ $(6.58 \mathrm{mg})$ and $\mathrm{C}(24.2 \mathrm{mg})$ as a white crystal.

\section{Biological properties}

Inhibition of lipid droplet formation in macrophages. In the control assay (no drug), mouse peritoneal macrophages accumulated a massive number of lipid droplets in the cytosol. In the presence of pentacecilides A and B at $0.21-24.3 \mu \mathrm{M}$, the size and number of lipid droplets in macrophages fell in a dose-dependent manner (data not shown). No morphological changes or cytotoxic effects were observed on macrophages even at the highest dose $(21.3-24.3 \mu \mathrm{M})$, indicating that pentacecilides $\mathrm{A}$ and $\mathrm{B}$ specifically inhibit lipid droplet formation in mouse macrophages. Pentacecilide $C$ showed almost no effect on lipid droplet formation in macrophages.

Inhibition of CE synthesis in macrophages. In the control assay (no drug), approximately $40 \%$ of exogenously added $\left[{ }^{14} \mathrm{C}\right]$ oleic acid was 

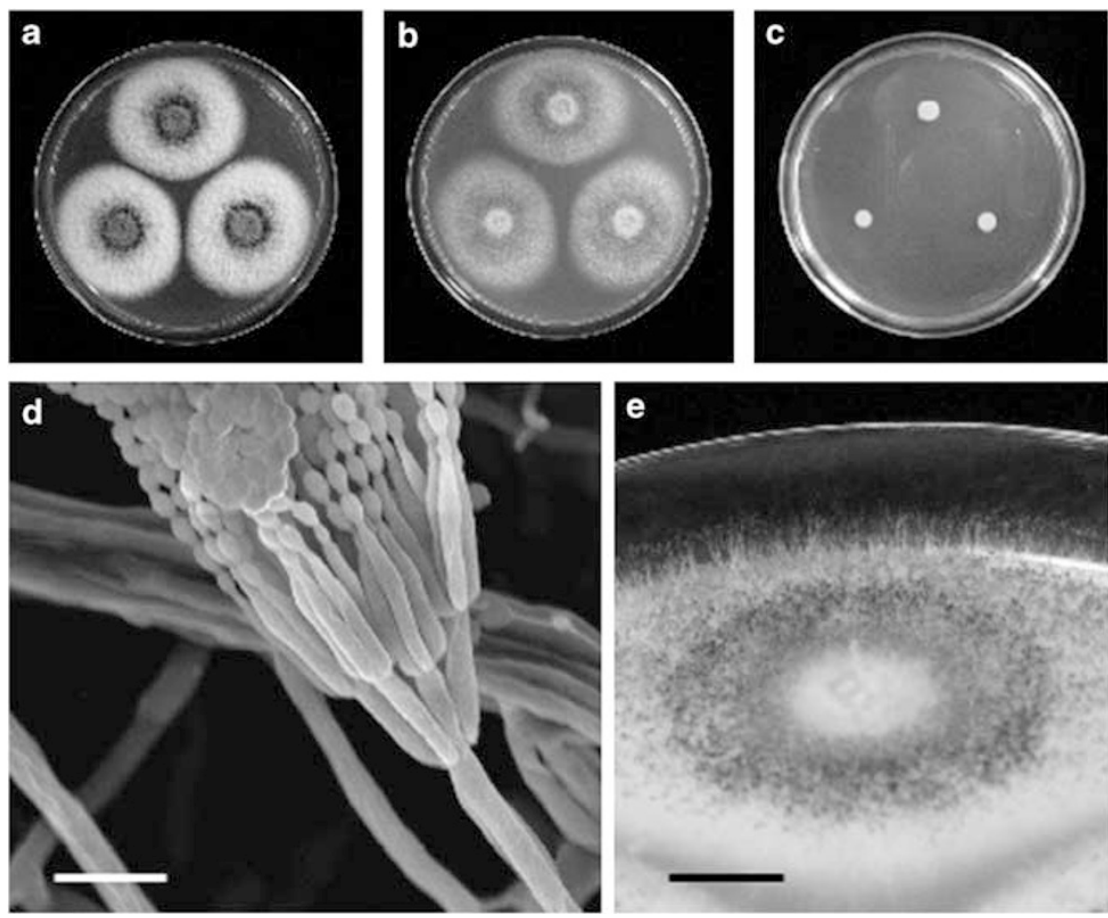

Figure 2 Morphological characteristics of pentacecilide-producing Penicillium cecidicola FKI-3765-1. (a) Micrography of colonies grown on Czapek yeast agar (CYA) after 7 days. (b) Micrograph of colonies grown on malt extract agar (MEA) after 7 days. (c) Micrograph colonies grown on G25N after 7 days. (d) Scanning electron micrograph of conidiophores grown on MEA. Scale bar, $10 \mu \mathrm{m}$. (e) Micrograph of synnemata grown on MEA. Scale bar, $10 \mathrm{~mm}$.

incorporated into $\left[{ }^{14} \mathrm{C}\right] \mathrm{CE}$ (approximately 25\%) and $\left[{ }^{14} \mathrm{C}\right] \mathrm{TG}$ (approximately 15\%), which are the main constituents of lipid droplets in macrophages. ${ }^{14}$ As shown in Figure 4, pentacecilides A and $\mathrm{B}$ inhibited $\left[{ }^{14} \mathrm{C}\right] \mathrm{CE}$ synthesis in a dose-dependent manner with $\mathrm{IC}_{50}$ values of 3.65 and $4.76 \mu \mathrm{M}$, respectively, but showed almost no inhibition of $\left[{ }^{14} \mathrm{C}\right] \mathrm{TG}$ synthesis even at the highest dose (20.6 and $21.3 \mu \mathrm{M}$ ), indicating that pentacecilides A and B selectively inhibit CE synthesis in macrophages. In contrast, pentacecilide $\mathrm{C}$ did not inhibit $\left[{ }^{14} \mathrm{C}\right] \mathrm{CE},\left[{ }^{14} \mathrm{C}\right] \mathrm{TG}$ and $\left[{ }^{14} \mathrm{C}\right] \mathrm{PL}$ synthesis. These data are comparable with the results of lipid droplet formation in macrophages, as described above.

Inhibition of post-lysosomal cholesterol metabolism in macrophages. To gain insight into the target molecule of pentacecilides in the inhibition of lipid droplet formation in macrophages, the effects of pentacecilides on the post-lysosomal process of cholesterol metabolism was studied. When macrophages were incubated with $\left[{ }^{14} \mathrm{C}\right]$ cholesterol-supplemented liposomes in the presence of $10 \mu \mathrm{m}$ pregnenolone, $\left[{ }^{14} \mathrm{C}\right] \mathrm{CE}$ formation was almost completely suppressed, and unesterified $\left[{ }^{14} \mathrm{C}\right]$ cholesterol accumulated in the lysosomes of macrophages. ${ }^{15}$ After pregnenolone was removed by washing the cells with buffer, the metabolism of lysosomal $\left[{ }^{14} \mathrm{C}\right]$ cholesterol to $\left[{ }^{14} \mathrm{C}\right] \mathrm{CE}$ was restarted in the presence or absence of pentacecilides. As shown in Figure $5 \mathrm{a}$, pentacecilides $\mathrm{A}$ and $\mathrm{B}$ inhibited $\left[{ }^{14} \mathrm{C}\right] \mathrm{CE}$ synthesis in a dose-dependent manner with $\mathrm{IC}_{50}$ values of 5.17 and $9.12 \mu \mathrm{M}$, respectively, which are within similar ranges to those for the synthesis of $\left[{ }^{14} \mathrm{C}\right] \mathrm{CE}$ from $\left[{ }^{14} \mathrm{C}\right]$ oleic acid (Figure 4). In contrast, pentacecilide $\mathrm{C}$ showed almost no effect, even at $24.3 \mu \mathrm{m}$. These data indicate that the inhibition site of pentacecilides A and B lies within the post-lysosomal steps in cholesterol metabolism.
Inhibition of ACAT activity in macrophage microsomes. The results using pregnenolone indicated that the inhibition site of pentacecilides is between the point of cholesterol departure from lysosomes and the point of cholesterol esterification in the endoplasmic reticulum. As epicochlioquinone, whose carbon skeleton and configuration are very similar to those of pentacecilides, is known to inhibit acyl-CoA: cholesterol acyltransferase (ACAT) activity, ${ }^{16}$ the effect of pentacecilides on ACAT activity was studied. For this purpose, microsomes prepared from mouse macrophages were used as an enzyme source. Pentacecilides A and B inhibited ACAT activity with $\mathrm{IC}_{50}$ values of 11.2 and $4.15 \mu \mathrm{M}$, respectively (Figure $5 \mathrm{~b}$ ). In contrast, pentacecilide $\mathrm{C}$ showed $50 \%$ inhibition at $24.3 \mu \mathrm{M}$.

Inhibition of CE synthesis in ACAT1- and ACAT2-CHO cells. From the macrophage assays, the potential target of pentacecilides $A$ and $B$ is deduced to be ACAT; therefore, the effect of pentacecilides on ACAT1 and ACAT2 isozymes was evaluated in ACAT1- and ACAT2CHO cells. As shown in Figure 6, pentacecilides A and B inhibited both ACAT1 and ACAT2 with similar potency. The respective $\mathrm{IC}_{50}$ values against ACAT1 and ACAT2 were 1.09 and $0.69 \mu \mathrm{M}$ for pentacecilide A and 10.8 and $3.97 \mu \mathrm{M}$ for pentacecilide B. These data indicated that pentacecilides A and B are dual inhibitors of ACAT1 and ACAT2.

\section{DISCUSSION}

As described in this study, three pentacecilides (Figure 1) were isolated from the culture broth of $P$. cecidicola FKI-3765-1; however, pentacecilides A and B were found to inhibit lipid droplet formation in mouse macrophages, whereas pentacecilide $\mathrm{C}$ showed no activity. These findings suggested that the hydroxy group at C-7 does not favor the inhibitory activity of lipid droplet formation in mouse macrophages. 


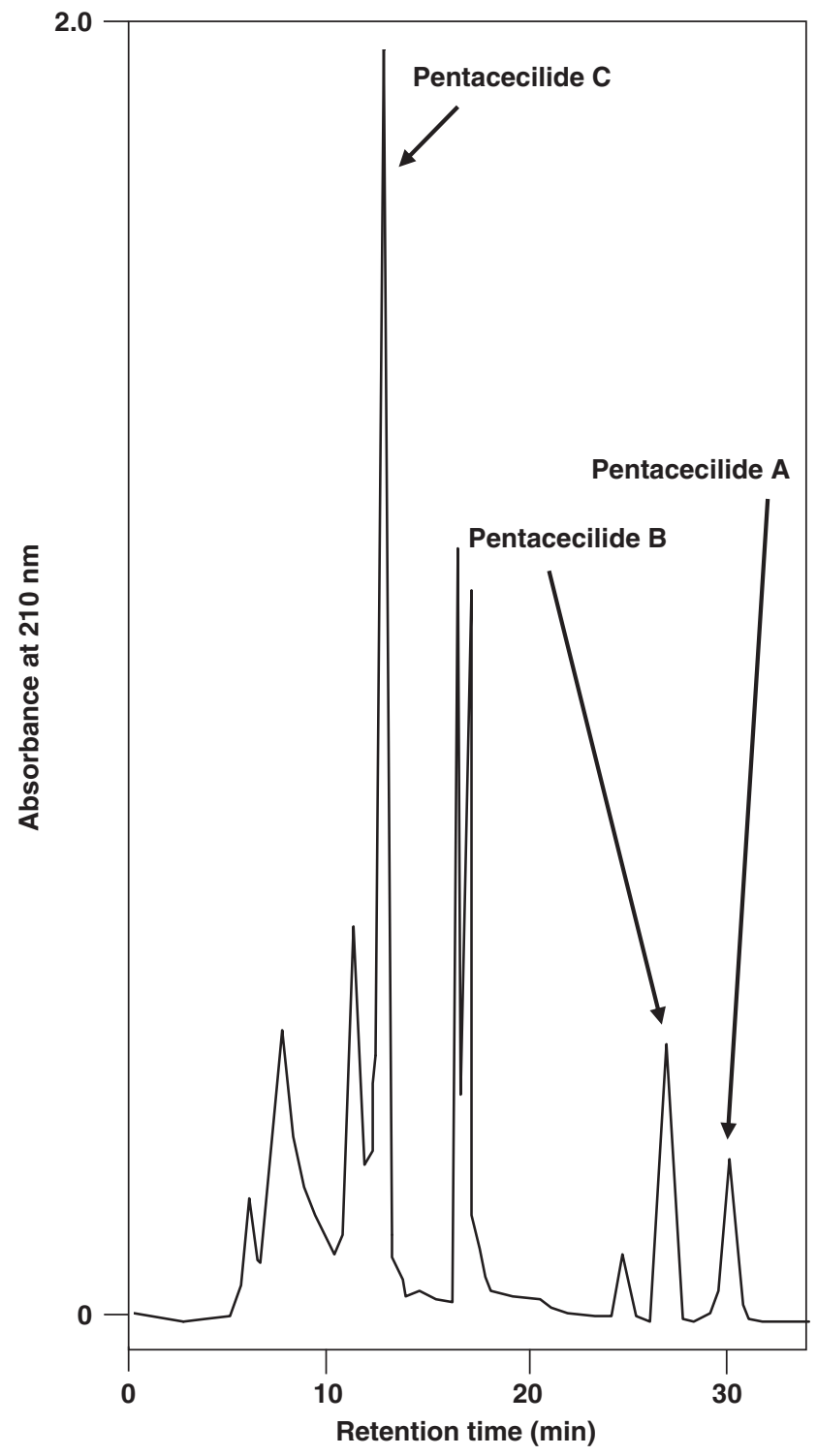

Figure $3 \mathrm{~A}$ chromatographic profile of pentacecilide purification by preparative HPLC. Column, PEGASIL ODS $(20 \times 250 \mathrm{~mm})$; solvent $70 \%$ aqueous acetonitrile; detection, UV at $210 \mathrm{~nm}$; flow rate, $8.0 \mathrm{ml} \mathrm{min}^{-1}$; sample, $35 \mathrm{mg}$ of active materials (obtained through silica gel column chromatography) dissolved in $700 \mu \mathrm{l}$ methanol.
Thailandolides (Figure 1), structurally related to pentacecilides, were not isolated from the culture broth of strain FKI-3765-1. As they have a hydroxy group at C-7 as well as pentacecilide $\mathrm{C}$, thailandolides might show no activity of lipid droplet formation in macrophages.

From a study of the action mechanism (Figures 4 and 5), we concluded that pentacecilides A and B inhibit ACAT activity in mouse macrophages to selectively block CE synthesis, leading to the inhibition of lipid droplet formation in mouse macrophages. Pentacecilide C showed almost no activity in these assays.

Pentacecilides $\mathrm{A}$ and $\mathrm{B}$ gave almost the same $\mathrm{IC}_{50}$ values in the cellbased assays (Figures 4 and $5 \mathrm{a}$ ), whereas pentacecilide $\mathrm{C}$ showed no effect in the cell-based assays (Figures 4 and $5 \mathrm{a}$ ). However, pentacecilide $\mathrm{C}$ showed weakly inhibitory activity in the microsomal assay (Figure $5 \mathrm{~b}$ ). The discrepancy of $\mathrm{IC}_{50}$ values between the assays might be due to the permeability of pentacecilide $\mathrm{C}$ to intact cells membrane, as our previously reported in the study of piperine. ${ }^{17}$ Furthermore, pentacecilides A and B are dual inhibitors of ACAT1 and ACAT2 isozymes.

\section{METHODS}

\section{General experimental procedures}

Fungal strain FKI-3765-1 was originally isolated from a soil sample collected in Hilo, Hawaii, USA. This strain was used for the production of pentacecilides A

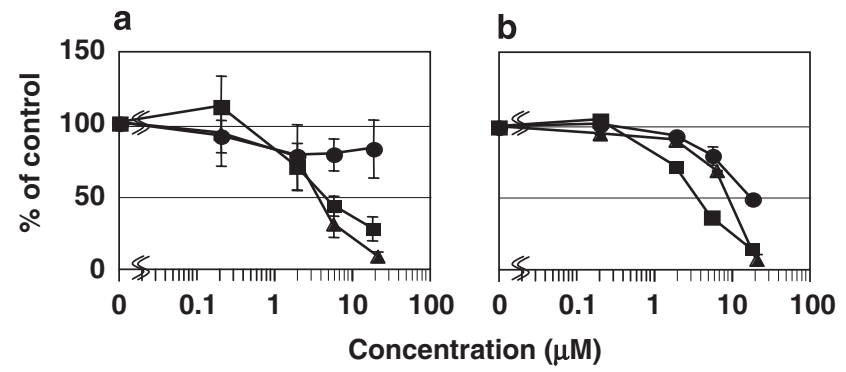

Figure 5 Effect of pentacecilides on $\left[{ }^{14} \mathrm{C}\right] \mathrm{CE}$ synthesis from lysosomal $\left[{ }^{14} \mathrm{C}\right]$ cholesterol in intact macrophages and on acyl-CoA: cholesterol acyltransferase (ACAT) activity in microsomes of mouse macrophages. (a) The amounts of $\left[{ }^{14} \mathrm{C}\right] \mathrm{CE}$ synthesized from lysosomal $\left[{ }^{14} \mathrm{C}\right] \mathrm{cholesterol}$ were determined in the presence of pentacecilides $\mathrm{A}(\mathbf{\Lambda}), \mathrm{B}(\mathbf{\square})$ and $\mathrm{C}(\bullet)$ as described in Methods. These results are plotted as a percent of control (without a drug). (b) ACAT activity in microsomes prepared from mouse macrophages was tested in the presence of pentacecilides $A(\mathbf{\Lambda}), B(\boldsymbol{\square})$ and $C(\bullet)$ as described in Methods. These results are plotted as a percent of the control (without a drug).
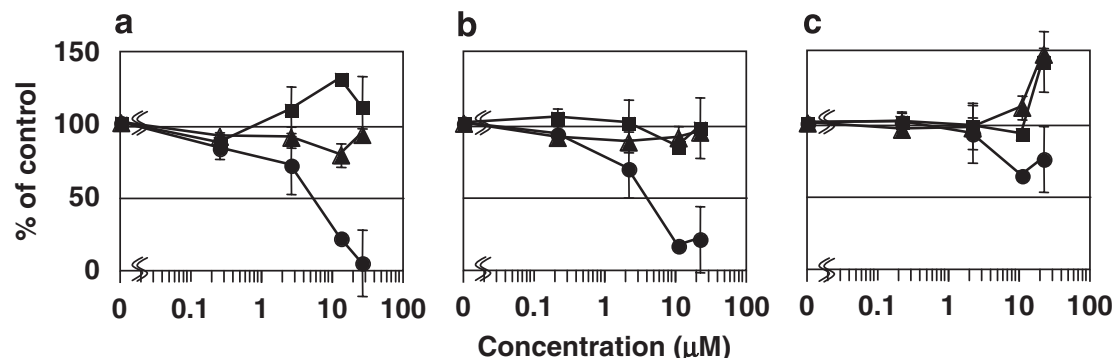

Figure 4 Effect of pentacecilides on the synthesis of $\left[{ }^{14} \mathrm{C}\right] \mathrm{CE},\left[{ }^{14} \mathrm{C}\right] \mathrm{TG}$ and $\left[{ }^{14} \mathrm{C}\right] \mathrm{PL}$ from $\left[{ }^{14} \mathrm{C}\right]$ oleic acid by macrophages. Macrophage monolayers obtained from $5 \times 10^{5}$ cells per well in a microplate were incubated in $0.25 \mathrm{ml}$ medium with a phospholipid/cholesterol liposome composed of phosphatidylcholine, phosphatidylserine, dicetylphosphate and cholesterol at a molar ratio $10: 10: 2: 15$ and $\left[{ }^{14} \mathrm{C}\right]$ oleic acid in the absence or presence of the indicated amounts of pentacecilides A (a), B (b) or C (c). After 14-h incubation, cholesteryl $\left[{ }^{14} \mathrm{C}\right]$ oleate $(\bullet),\left[{ }^{14} \mathrm{C}\right] \mathrm{TG}(\mathbf{\square})$ and $\left[{ }^{14} \mathrm{C}\right] \mathrm{PL}(\mathbf{\Delta})$ were separated on TLC, determined with a radioscanner as described in Methods. The results are plotted as a percent of the control (without a drug). 


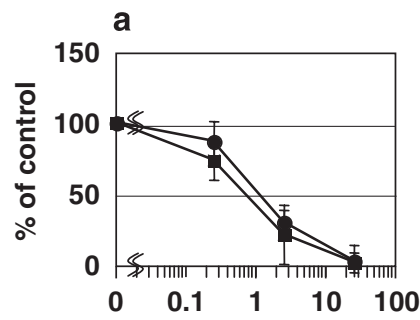

b

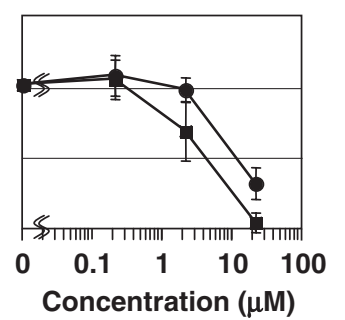

C

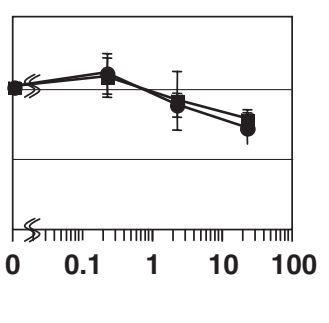

Figure 6 Effect of pentacecilides on $\left[{ }^{14} \mathrm{C}\right] \mathrm{CE}$ synthesis from $\left[{ }^{14} \mathrm{C}\right]$ oleic acid in ACAT1- or ACAT2-CHO cells. ACAT1- $(\bullet)$ or ACAT2-CHO ( $\left.\mathbf{\square}\right)$ cell monolayers $\left(1.25 \times 10^{5}\right.$ cells per well) in a microplate were incubated in the absence or presence of the indicated amounts of pentacecilides A (a), B (b) or C (c). After a 6 -h incubation, $\left[{ }^{14} \mathrm{C}\right] \mathrm{CE}$ was separated by TLC, and quantified with a bioimage analyzer, as described in Methods. The amounts of $\left[{ }^{14} \mathrm{C}\right] \mathrm{CE}$ signals were plotted as a percent of the control (without drugs).

to C. Kieselgel 60 (Merck KGaA, Darmstadt, Germany) was used for silica gel column chromatography. HPLC was carried out using the L-6200 system (Hitachi Ltd, Tokyo, Japan). To determine the amounts of pentacecilides A to C in culture broths, the samples (ethyl acetate extracts) dissolved in methanol were analyzed by the HP1100 system (Hewlett-Packard Company, Palo Alto, CA, USA) under the following conditions: column, Symmetry $(2.1 \times 150 \mathrm{~mm}$; Waters Corporation, Milford, MA, USA); flow rate, $0.2 \mathrm{ml} \mathrm{min}^{-1}$; mobile phase, a 20-min linear gradient from $60 \% \mathrm{CH}_{3} \mathrm{CN}$ to $100 \% \mathrm{CH}_{3} \mathrm{CN}$ containing $0.05 \% \mathrm{H}_{3} \mathrm{PO}_{4}$; detection, $\mathrm{UV}$ at $210 \mathrm{~nm}$. Under these conditions, pentacecilides A to $\mathrm{C}$ were eluted with a retention time of $9.01,8.71$ and $4.67 \mathrm{~min}$, respectively.

\section{Taxonomic studies of the producing strain FKI-3765-1}

Morphological studies and identification were conducted according to the procedures described by Pitt. ${ }^{13}$ For taxonomic studies, CYA, malt extract agar and $25 \%$ glycerol nitrate agar (G25N) were used. Morphological characteristics were observed under a light microscope (Vanox-S AH-2, Olympus Corporation, Tokyo, Japan) and scanning electron microscope (JSM-5600, JEOL Ltd, Tokyo, Japan). Color names and hue numbers were determined according to the Color Harmony Manual. ${ }^{18}$ For molecular phylogenetic study, genomic DNA was extracted using the PrepMan Ultra Sample Preparation Reagent (Applied Biosystems Inc., Foster City, CA, USA) according to the manufacturer's protocol. The rDNA internal transcribed spacer (rDNAITS) regions, including the $5.8 \mathrm{~S}$ rDNA gene, were amplified by PCR using primers ITS1 and ITS4. ${ }^{19}$ Amplifications were performed using a PCR Thermal Cycler Dice mini Model TP100 (Takara Bio Inc., Shiga, Japan). The amplified PCR products were purified using a QIAquick PCR DNA Purification Kit (Qiagen Inc., Valencia, CA, USA). Sequencing reactions were directly performed using a BigDye Terminator v3.1 Cycle Sequencing Kit (Applied Biosystems Inc.), and the products were purified with a DyeEX 2.0 Spin Kit (Qiagen Inc.). DNA sequences were read on an ABI PRISM 3130 Genetic Analyzer (Applied Biosystems Inc.) and assembled using the programs SeqMan and SeqBuilder from the Lasergene7 package (DNAStar Inc., Madison, WI, USA). The ITS region rDNA sequence was compared with the database of the National Center for Biotechnology Information, Japan. ITS was deposited in DDBJ with accession number AB457008.

\section{Fermentation}

A slant culture of strain FKI-3765-1 grown on LCA (glycerol 0.10\%, $\mathrm{KH}_{2} \mathrm{PO}_{4}$ $0.08 \%, \mathrm{~K}_{2} \mathrm{HPO}_{4} 0.02 \%, \mathrm{MgSO}_{4} 7 \mathrm{H}_{2} \mathrm{O} 0.02 \%, \mathrm{KCl} 0.02 \%, \mathrm{NaNO}_{3} 0.20 \%$, yeast extract $0.02 \%$, agar $1.5 \%, \mathrm{pH} 6.0$ ) was inoculated into a $50-\mathrm{ml}$ tube containing $10 \mathrm{ml}$ of the seed medium (glucose $2.0 \%$, polypeptone $0.50 \%, \mathrm{MgSO}_{4} 7 \mathrm{H}_{2} \mathrm{O}$ $0.05 \%$, yeast extract $0.20 \%, \mathrm{KH}_{2} \mathrm{PO}_{4} 0.10 \%$, agar $0.10 \%$, $\mathrm{pH} 6.0$ ). The tube was shaken on a reciprocal shaker for 3 days at $27^{\circ} \mathrm{C}$. A $1 \mathrm{ml}$ portion of the seed culture was then inoculated into a 500-ml Erlenmeyer flask containing the production medium $(50 \mathrm{~g}$ Italian rice, Japan Europe Trading Co. Ltd, Tokyo, Japan). Fermentation was carried out at $27^{\circ} \mathrm{C}$ for 15 days under stable conditions.
Assay for lipid droplet formation in mouse macrophages

The assay for lipid droplet formation in mouse macrophages was carried out according to our established method. ${ }^{20}$

\section{Assay for lipid synthesis by mouse macrophages}

An assay for the synthesis of CE, TG and phospholipids by mouse macrophages was carried out according to the method described earlier. ${ }^{20}$

Assay for lysosomal cholesterol metabolism in mouse macrophages The metabolism of lysosomal $\left[{ }^{14} \mathrm{C}\right]$ cholesterol in mouse macrophages was measured as described earlier. ${ }^{14}$

Assay for ACAT activity in mouse macrophage microsomes Acyl-CoA: cholesterol acyltransferase activity was assayed according to our established method. ${ }^{21}$

\section{Culture of ACAT1- and ACAT2-CHO Cells}

Two cell lines, CHO cells expressing acyl-CoA: cholesterol acyltransferase 1 (ACAT1) and 2 (ACAT2) isozymes of African green monkey (ACAT1- and ACAT2-CHO cells, respectively) ${ }^{15}$ were kind gifts from Dr LL Rudel (Wake Forest School of Medicine, NC). Cells were maintained as described earlier. ${ }^{22}$

\section{Assay for ACAT1 and ACAT2 activities using ACAT1- and ACAT2-CHO cells}

An assay for ACAT1 and ACAT2 activities in ACAT1- and ACAT2-CHO cells was carried out by our established method. ${ }^{22}$

\section{ACKNOWLEDGEMENTS}

We thank Mr N Ugaki for excellent technical assistance. This study was supported by the Program for the Promotion of Fundamental Studies in Health Sciences (to HT) from the National Institute of Biomedical Innovation (NIBIO).

1 Goldstein, J. L., Ho, Y. K., Basu, S. K. \& Brown, M. S. Binding site on macrophages that mediates uptake and degradation of acetylated low density lipoprotein, producing massive cholesterol deposition. Proc. Natl Acad. Sci. USA 76, 333-337 (1979).

2 Brown, M. S., Goldstein, J. L., Krieger, M., Ho, Y. K. \& Anderson, R. G. W. Reversible accumulation of cholesteryl esters in macrophages incubated with acetylated lipoproteins. J. Cell Biol. 82, 597-613 (1979).

3 Scaffner, T. et al. Arterial foam cells with distinctive immunomorphological and histochemical features of macrophages. Am. J. Pathol. 100, 57-73 (1980).

4 Gerrtiy, R. G. The role of the monocyte in atherogenesis. I. Transition of blood-borne monocytes into foam cells in fatty lesions. Am. J. Pathol. 103, 181-190 (1981).

5 Namatame, I. et al. Beauveriolides, specific inhibitors of lipid droplet formation in mouse macrophages, produced by Beauveria sp. FO-6979. J. Antibiot. 52, 1-6 (1999).

6 Namatame, I., Tomoda, H., Ishibashi, S. \& Ōmura, S. Antiatherogenic activity of fungal beauveriolides, inhibitors of lipid droplet accumulation in macrophages. Proc. Natl Acad. Sci. USA 101, 737-742 (2004) 
7 Tomoda, H. et al. Phenochalasins, inhibitors of lipid droplet formation in mouse macrophages, produced by Phomopsis sp. FT-0211. J. Antibiot. 52, 851-856 (1999).

8 Namatame, I. et al. K97-0239A and B, new inhibitors of macrophage foam cell formation, produced by Streptomyces sp. K97-0239. Proc. Japan Acad. 78B, 45-50 (2002).

9 Koyama, N. et al. Spylidone, a novel inhibitor of lipid droplet accumulation in mouse macrophages by Phoma sp. FKI-1840. J. Antibiot. 58, 338-345 (2005).

10 Koyama, N., Ohshiro, T., Tomoda, H. \& Ōmura, S. Fungal isobisverthinol, a new inhibitor of lipid droplet accumlation in mouse macrophage. Org. Lett. 9, 425-428 (2007).

11 Dethoup, T. et al. Merodrimanes and other constituents from Talaromyces thailandiasis. J. Nat. Pro. 70, 1200-1202 (2007)

12 Yamazaki, H., Ōmura, S. \& Tomoda, H. Pentacecilides, new inhibitors for lipid droplet formation in mouse macrophages produced by Penicillium cecidicola FKI-3765-1. II Physico-chemical properties and structure elucidation. J. Antibiot. 62, 207-211 (2009).

13 Pitt, J. I. The Genus Penicillium, and its Teleomorphic States Eupenicillium and Talaromyces. Academic Press, London: 1-634 (Academic Press: London, 1979).

14 Furuchi, T., Aikawa, K., Arai, H. \& Inoue, K. Bafilomycin A1, a specific inhibitor of vacuolar-type $\mathrm{H}(+)$-ATPase, blocks lysosomal cholesterol trafficking in macrophages. J. Biol. Chem. 268, 27345-27348 (1993).
15 Lada, A. T. et al. Identification of ACAT1- and ACAT2-specific inhibitors using a novel, cell-based fluorescence assay: individual ACAT uniqueness. J. Lipid. Res. 45, 378-386 (2004).

16 Fujioka, T. et al. Epi-cochlioquinone A, a novel acyl-CoA:cholesterol acyltransferase inhibitor produced by Stachybotrys bisbyi. J. Antibiot. 49, 409-413 (1996).

17 Matsuda, D. et al. Molecular target of piperine in the inhibition of lipid droplet accumulation in macrophages. Biol. Pharm. Bull. 31, 1063-1066 (2008).

18 Jacobson, E., Granville, W. C. \& Foss, C. E. Color Harmony Manual, 4th edn. (Container of America: Chicago, 1958).

19 White, T. J., Bruns, T., Lee, S. \& Taylor, J. W. Amplification and direct sequencing of fungal ribosomal RNA genes for phylogenetics. in PCR protocols: a guide to methods and applications. (Innis MA, Gelfand RH, Sninsky JJ, White TJ, eds). 315-332 (Academic Press, New York, 1990).

20 Namatame, I., Tomoda, H., Arai, H., Inoue, K. \& Ōmura, S. Complete inhibition of mouse macrophage-derived foam cell formation by triacsin C. J. Biochem. 125, 319-327 (1999).

21 Ohshiro, T. et al. Absolute stereochemistry of fungal beauveriolide III and ACAT inhibitory activity of four stereoisomers. J. Org. Chem. 71, 7643-7649 (2006).

22 Ohshiro, T., Rudel, L. L., Ōmura, S. \& Tomoda, H. Selectivity of microbial acyl-CoA: cholesterol acyltransferase inhibitors toward isozymes. J. Antibiot. 60, 43-51 (2007). 